\title{
Imaging Confirmation of Yo-Yo Reflux in Cases with Incomplete Ureteric Duplication
}

\author{
Ashraf Talaat Youssef \\ Department of Radiodiagnosis, Faculty of Medicine, Fayoum University, Al Fayoum, Egypt \\ Email: ashraftalaat1@yahoo.com
}

How to cite this paper: Youssef, A.T. (2016) Imaging Confirmation of Yo-Yo Reflux in Cases with Incomplete Ureteric Duplication. Open Journal of Urology, 6, 199-205. http://dx.doi.org/10.4236/oju.2016.612031

Received: December 25, 2016

Accepted: December 18, 2016

Published: December 21, 2016

Copyright (@) 2016 by author and Scientific Research Publishing Inc. This work is licensed under the Creative Commons Attribution International License (CC BY 4.0).

http://creativecommons.org/licenses/by/4.0/

(c) (†) Open Access

\begin{abstract}
Background: Incomplete ureteric duplication can be associated with either ureteropelvic obstruction involving the lower moiety or reflux between the ureters (yo-yo reflux). Yo-yo reflux can be a cause of repeated urinary tract infection with subsequent renal damage. Aim of the work: The current study evaluated the presence of yo-yo reflux as reason of upper moiety dilation in cases with incomplete duplication of upper urinary tract. Methodology: 10 cases with a dilated upper moiety of duplex renal pelvicalyceal system were examined with color duplex ultrasonography. All were further investigated with intravenous pyelography (IVP), and ascending/micturating cystography. Results: 9 cases with upper moiety dilation showed complete duplication of the pelvicalyceal systems and ureters and 1 case with dilated upper moiety showed incomplete ureteric duplication in which the diagnosis of Yo-yo reflux was confirmed by color duplex ultrasound in addition to the intravenous pyelography findings. Conclusion: The presence of antegrade/retrograde flow within the dilated moiety of a duplex kidney during color duplex study in addition to the intravenous pyelography findings can confirm the diagnosis of yo-yo reflux.
\end{abstract}

\section{Keywords}

Yo-Yo Reflux, Ureteric Duplication, Duplex Kidney, Color Duplex Sonography

\section{Introduction}

A duplex collecting system is a common congenital anomaly of the urinary tract [1]. Duplex collecting system can be classified into duplex kidney with 2 separate pelvicalyceal systems. Duplex kidney drains into single, bifid, or double ureters. A bifid pelvicalyceal system drains into one pelviureteric junction or double ureters [2]. Incomplete ureteric duplication can be associated with either ureteropelvic obstruction involving the lower moiety or reflux between the ureters (yo-yo reflux) [3]. Yo-yo reflux can be a 
cause of repeated urinary tract infection with subsequent renal damage [4]. So every effort should be done to rule out the presence of yo-yo reflux in cases with duplicated collecting system.

Various radiological modalities used to investigate the abnormalities of renal collecting system include intravenous pyelography, ascending/micturating cystography [5] [6] [7], computed tomography [8] and magnetic resonance urography [9] [10].

Few imaging trials were recorded for imaging of yo-yo reflux by isotope scan [11], and one case report with color Duplex sonography [3].

\section{The Aim of the Work}

The current study evaluated the presence of yo-yo reflux as reason of upper or lower moiety dilation in cases with incomplete duplication of upper urinary tract.

\section{Methodology}

10 cases with a dilated upper moiety of duplex renal pelvicalyceal systems were examined with color duplex ultrasonography from December 2015 to August 2016 at a private radiology center using a Sonoace X8 ultrasound machine (Medison, Korea). All were examined with convex probe of frequency 3.5 MHZ.

The patients were examined after an Informed consent was given by their parents prior to the study, with B mode ultrasound and with color and pulsed Doppler sonography to evaluate the presence of antegrade/retrograde flow within the collecting system, all were examined in supine, prone position during full urinary bladder and after micturation. Their ages ranged from 5 to 12 years old. 2 cases were incontinent of urine, 2 cases were presented with repeated urinary tract infection and the other 6 cases were asymptomatic and discovered incidentally. All were further investigated with intravenous pyelography (IVP), and ascending/micturating cystography.

\section{Results}

9 cases with upper moiety dilation showed complete duplication of the pelvicalyceal systems and ureters, among them 3 cases with ectopic ureteric insertion into the upper vagina, bladder neck and posterior urethra, one case with normal ureteric insertion and vesicoureteric reflux and the other 5 cases with terminal ureteric ureteroceles.

8 cases showed no color flow within the dilated pelvicalyceal system by color duplex US (Figure 1) and one case showed color changes representing both antegrade and retrograde weak flow at the dilated upper moiety suggesting of high grade reflux. One case was a female child aged 5 years was presented with localized cyst related to the upper pole of the right kidney The kidney showed duplex pelvicalyceal system and the cyst related to the upper pole showed no arterial or venous flow pattern and seen representing mildly dilated upper moiety of the duplex pelviclayceal system (Figure 2).

The dilated upper moiety showed alternating red and blue color flow signal inside (Figure 3) with both antegrade and retrograde flow with pulsed Doppler sonography suggesting reflux (Figure 4). So the patient was subjected to an intravenous pyelography 


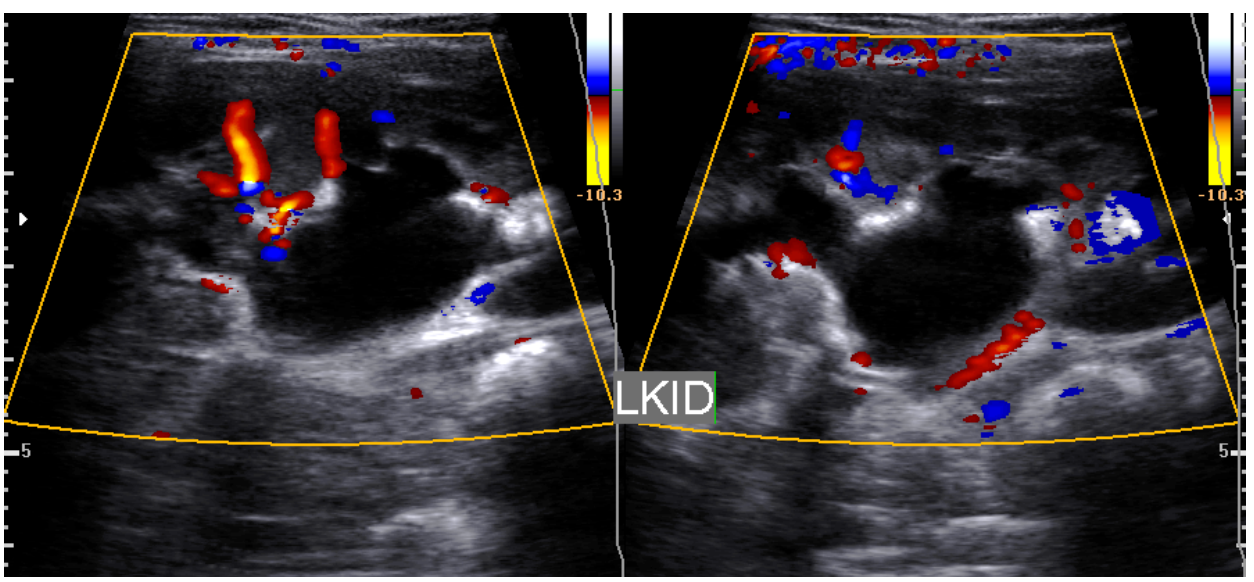

Figure 1. Color duplex sonography showing obstructive dilation of upper left renal moiety with no color changes within the dilated pyelocalyceal group.
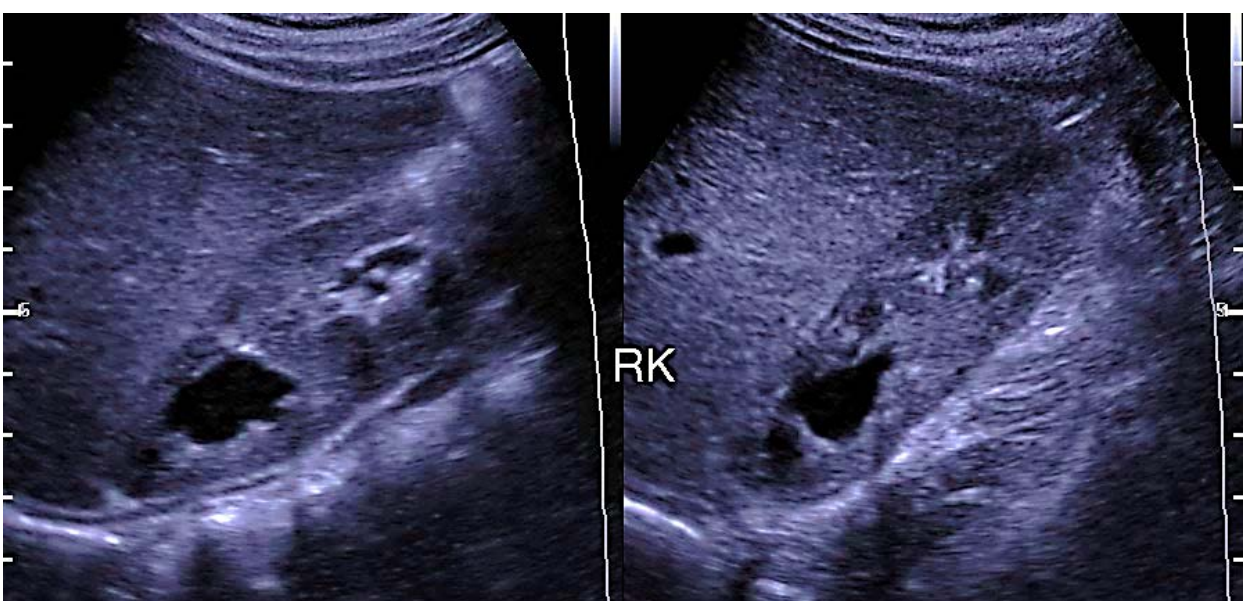

Figure 2. Real time sonography showing dilated upper moiety of duplex right kidney.

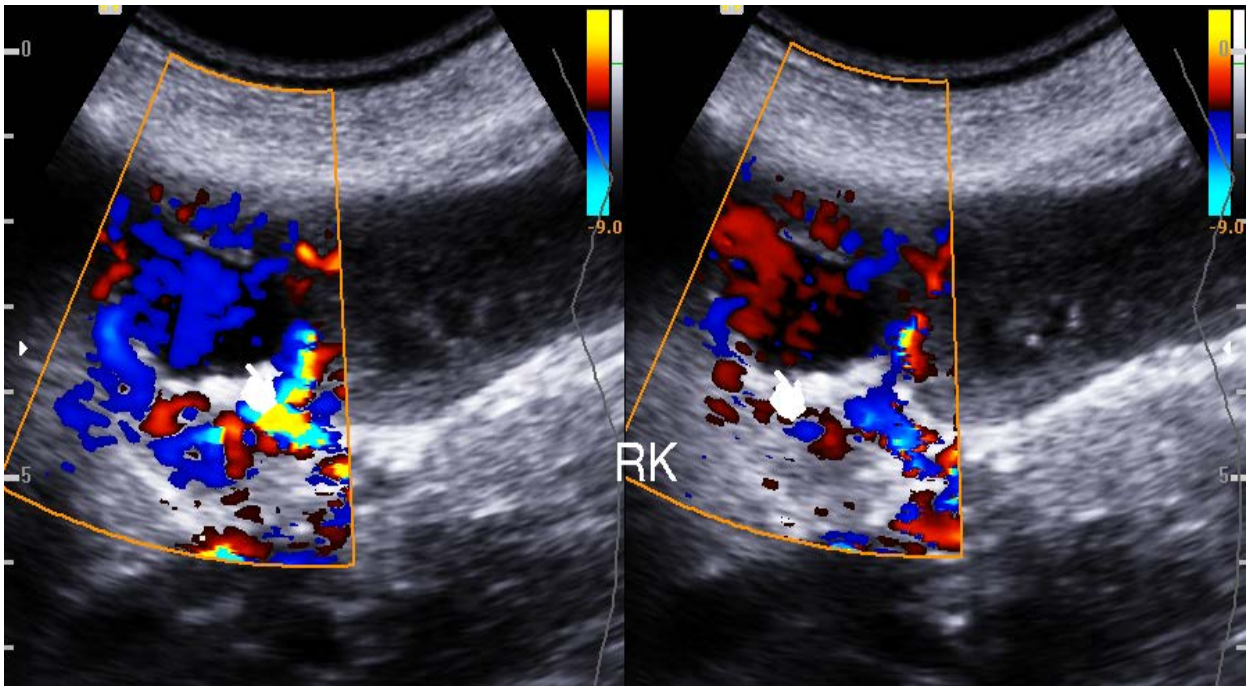

Figure 3. Color duplex sonography showing antegrade/retrograde flow suggested by the color changes within the dilated upper moiety of the duplex right kidney (indicator). 


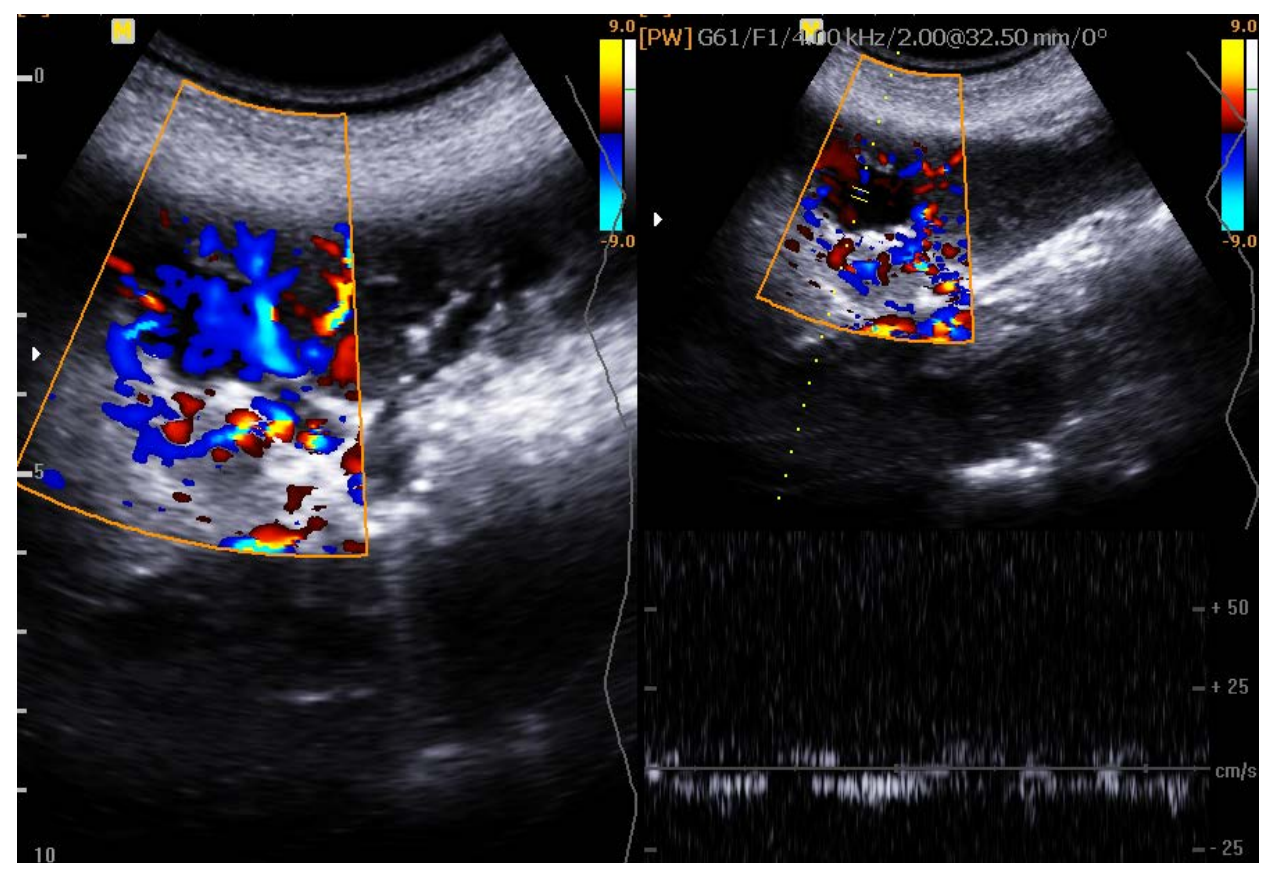

Figure 4. Color Doppler and pulsed Doppler study demonstrating antegrade and retrograde flow within the dilated upper moiety of right kidney confirming reflux.

(IVP) exam. The result of IVP showed incomplete duplication of upper right sided urinary tract with 2 ureters seen uniting at the level of $5^{\text {th }}$ lumbar vertebrae (Figure 5, Figure 6), no signs of obstruction seen with mildly dilated upper moiety ureter and the draining pelvicalyceal system. Both color duplex sonography and IVP findings confirm the presence of yo-yo reflux between the lower moiety and upper moiety ureters at the site of their union.

The patient was advised to follow up and conservative management since no gross dilation of the upper moiety observed and no history of repeated urinary tract infection.

\section{Discussion}

The differential diagnosis of duplex upper urinary tract with dilated upper moiety includes complete duplication of the collecting system with 2 pyeolcalyceal systems and duplicated ureters, the upper moiety ureter was subjected to obstruction by terminal ureterocele with stenotic meatus or can be subjected to ectopic insertion with subsequent more liability to reflux. In an incomplete ureteric duplication the ureters fuse while they descend to reach the urinary bladder with subsequent reflux between the high pressure ureter and low pressure ureter which is usually the upper ureter with subsequent upper ureteric and upper moiety dilatation. The presence of alternating color flow signal detected at the upper moiety and the antegrade/retrograde flow with pulsed Doppler suggesting reflux will exclude the presence of obstruction due to terminal ureterocele associated with complete ureteric duplication, also only single color jet was originating in the urinary bladder (ureteric jet) is not suggesting of but not totally 


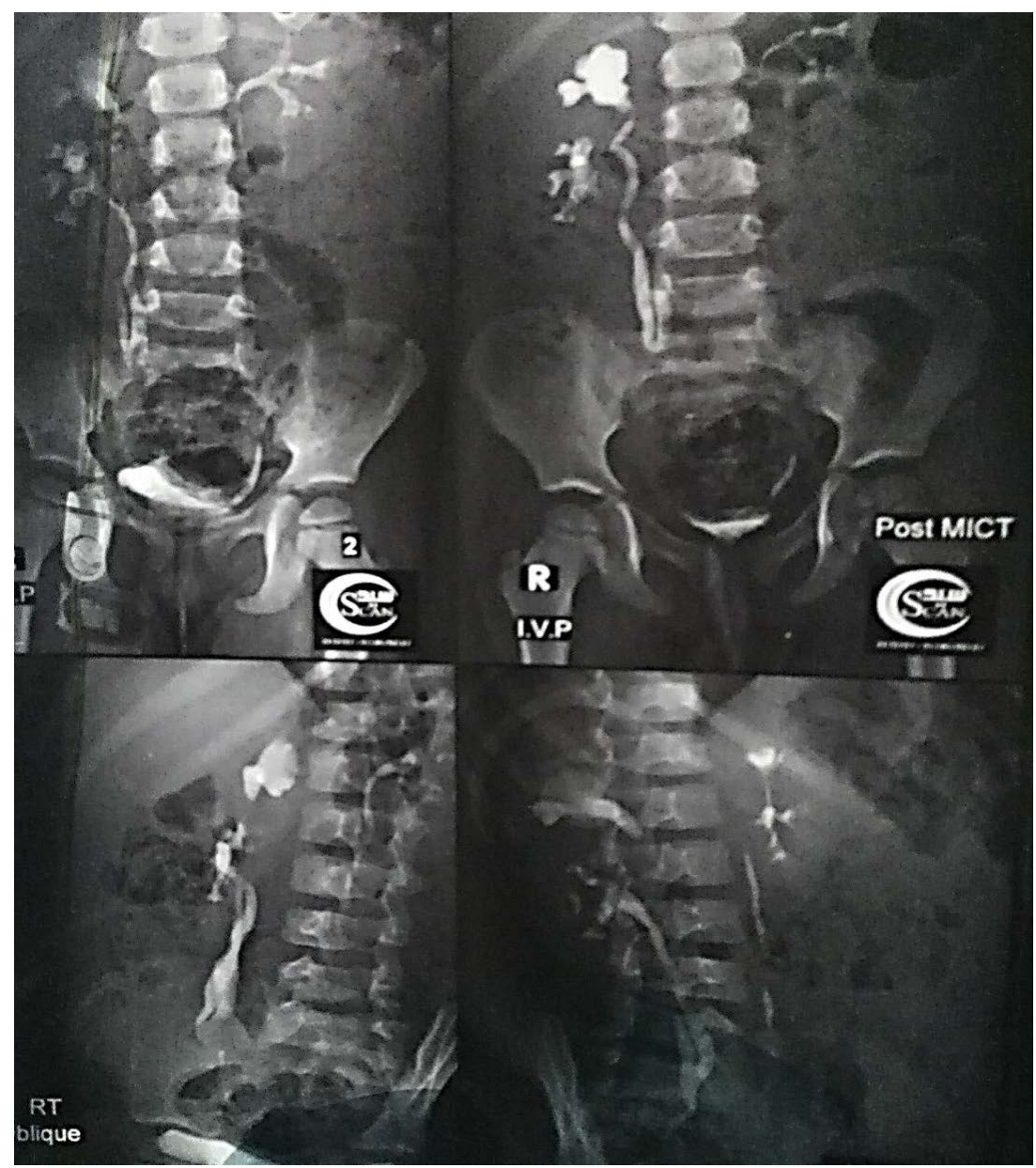

Figure 5. IVP exam showing duplex pyelocalyceal system of the right kidney with partially duplicated ureters seen fused opposite to the level of L5 vertebrae with proximally dilated upper ureter and upper moiety.

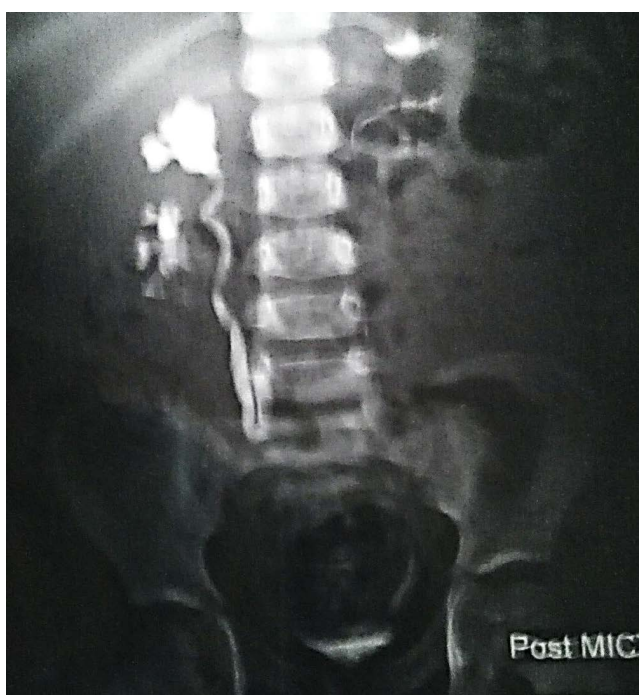

Figure 6. Post micturation IVP shows partially duplicated ureters with dilated upper collecting system on the right side. 
excluding the presence of complete duplication since the upper moiety ureter may show ectopic insertion.

Perhaps the short distance of refluxing jet to reach the upper moiety in an incomplete duplication with Yo-Yo reflux plays a role in the observation of color changes. While in case with complete ureteric duplication and ectopic ureteric insertion the presence of color changes within the dilated moiety will be only observed with high grade reflux and will lead to markedly dilated pelvicalyceal group and low grade reflux will not show color changes and may not show dilated calyces

So the presence of color changes in mildly dilated moiety of duplex kidney will raise the possibility of incomplete ureteric dilation and subsequent yo-yo reflux, while the presence of markedly dilated moiety in the presence of color changes will lead to the possibility of complete duplication with ectopic insertion of the ureter, and the absence of color changes within a dilated moiety will raise the possibility of complete duplication and terminal ureteric obstruction.

The use of both intravenous pyelography and color duplex sonography can confirm the presence of yo-yo reflux if partially duplicated ureter and dilated one moiety was detected with IVP in addition to the presence of antegrade/retrograde flow within the dilated moiety with color duplex sonography.

\section{Conclusion}

Yo-yo reflux is an uncommon cause of dilated upper moiety of duplex kidney, but should be considered when observing antegrade and retrograde flow within the dilated pyelocalyceal group by color duplex sonography in addition to the presence of incomplete ureteric duplication by intravenous pyelography.

\section{References}

[1] Gay, S.B., Armistead, J.P., Weber, M.E., et-al. (1991) Left Infrarenal Region: Anatomic Variants, Pathologic Conditions, and Diagnostic Pitfalls. Radiographics, 11, 549-570. https://doi.org/10.1148/radiographics.11.4.1887111

[2] Glassberg, K.I., Braren, V., Duckett, J.W., Jacobs, E.C., King, L.R., Lebowitz, R.L, et al. (1984) Suggested Terminology for Duplex Systems, Ectopic Ureters and Ureteroceles. The Journal of Urology, 132, 1153-1154.

[3] Gupta, K., Galhotra, R. and Saggar, K. (2013) Yo-Yo Reflux in Partial Duplication of Ureter: A Diagnosis on the Color and Pulse Doppler Study. Muller Journal of Medical Sciences and Research, 4, 116-188. https://doi.org/10.4103/0975-9727.118243

[4] Fernbach, S.K., Feinstein, K.A., Spencer, K. and Lindstrom, C.A. (1997) Ureteral Duplication and Its Complications-Scientific Exhibit. Radiographics, 17, 109-127. https://doi.org/10.1148/radiographics.17.1.9017803

[5] Doery, A.J., Ang, E. and Ditchfield, M.R. (2015) Duplex Kidney: Not Just a Drooping Lily. Journal of Medical Imaging and Radiation Oncology, 59, 149-153. https://doi.org/10.1111/1754-9485.12285

[6] Chertin, B., Mohanan, N., Farkas, A., et al. (2007) Endoscopic Treatment of Vesicoureteral Reflux Associated with Ureterocele. The Journal of Urology, 178, 1594-1597.

[7] Lebowitz, R.L. and Avni, F.E. (1980) Misleading Appearances in Pediatric Uroradiology. 
Pediatric Radiology, 10, 15-31.

[8] Blair, D., Rigsby, C. and Rosenfield, A.T. (1987) The Nubbin Sign on Computed Tomography and Sonography. Urologic Radiology, 9, 149-151.

[9] Avni, F.E., Nicaise, N., Hall, M., et al. (2001) The Role of MR Imaging for the Assessment of Complicated Duplex Kidneys in Children: Preliminary Report. Pediatric Radiology, 31, 215-223. https://doi.org/10.1007/s002470100439

[10] Yanagisawa, N., Yajima, M., Takahara, T., et al. (1997) Diagnostic Magnetic ResonanceUrography in an Infant Girl with an Ectopic Ureter Associated with a Poorly Functioning Segment of a Duplicated Collecting System. International Journal of Urology, 4, 314-317. https://doi.org/10.1111/j.1442-2042.1997.tb00198.x

[11] Chu, W.C., Chan, K.W. and Metreweli, C. (2003) Scintigraphic Detection of "Yo-Yo" Phenomenon in Incomplete Ureteric Duplication. Pediatric Radiology, 33, 59-61.

https://doi.org/10.1007/s00247-002-0754-Z

Submit or recommend next manuscript to SCIRP and we will provide best service for you:

Accepting pre-submission inquiries through Email, Facebook, LinkedIn, Twitter, etc.

A wide selection of journals (inclusive of 9 subjects, more than 200 journals)

Providing 24-hour high-quality service

User-friendly online submission system

Fair and swift peer-review system

Efficient typesetting and proofreading procedure

Display of the result of downloads and visits, as well as the number of cited articles

Maximum dissemination of your research work

Submit your manuscript at: http://papersubmission.scirp.org/

Or contact oju@scirp.org 